\section{В. В. Елисеев}

ЧАО «Северодонецкое научно-производственное объединение «Импульс», г. Северодонецк,

Луганская область, Украина

\section{Информационные}

\section{и управляющие системы АЭС производства СНПО «Импульс».}

\section{Состояние, перспективы}

Рассмотрены основные особенности информационных и управ ляющих систем (ИУС) атомных электростанций производства СНПО «Импульс», при создании которых учтены современные тенденции в реализации АСУ ТП перспективных энергоблоков: возможность по строения ИУС с различными схемами мажорирования; устойчивость к единичным и кратным неисправностям за счет резервированных структур; применение принципов диверсности; минимум кабельных связей благодаря применению выносных цифровых контроллеров для дистанционного управления, индикации и сигнализации на блок щитового управления, цифровой оптической передачи данных. Приведены сведения о внедрениях, технических и программных средствах ИУС.

Ключевые слова: ИУС АЭС, АСУ ТП, аппаратно-программная платформа ИуС.

\section{В. В. Єлісєєв}

Інформаційні та керуючі системи АEC виробництва СНвО «Імпульс». Стан, перспективи

Розглянуто основні особливості інформаційних та керуючих систем (IKC) атомних електростанцій виробництва СНВО «Імпульс», у процесі створення яких враховано сучасні тенденції в реалізації АСУ ТП перспективних енергоблоків: можливість побудови IКС з різними схе мами мажорування; стійкість до одиничних і кратних несправностей за рахунок резервованих структур; застосування принципів диверсності; мінімум кабельних зв'язків завдяки застосуванню виносних цифрових контролерів для дистанційного керування, індикації та сигналізації на блок щитового управління, цифрової оптичної передачі даних. Наведено відомості щодо впроваджень, технічних і програмних засобів IKC.

Ключові слова: IKC AEC, АСУ ТП, апаратно-програмна платформа IKC

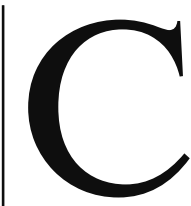
еверодонецкое НПО «Импульс» (СНПО «Импульс») - разработчик, производитель и поставщик высоконадежных цифровых информационных и управляющих систем АЭС: цифровых управляющих систем безопасности, цифровых управляющих систем нормальной эксплуатации реакторного и турбинного отделений, систем группового и индивидуального управления стержнями, систем контроля нейтронного потока, информационно-вычислительных систем верхнего блочного уровня, систем внутриреакторного контроля, комплексных систем диагностики и др.

Информационные и управляющие системы (ИУС) производства СНПО «Импульс» охватывают практически полный диапазон систем АСУ ТП энергоблока АЭС.

За последнее десятилетие в Украине, России, Армении предприятием (в том числе по программам НАЭК «Энергоатом», TACIS и INSC) внедрены около 120 ИУС, важных для безопасности АЭС, в частности:

- информационно-вычислительная система верхнего блочного уровня [1] - на Хмельницкой АЭС (энергоблоки №№ 1, 2); Ровенской АЭС, энергоблоки №№ 1-4; Запорожской АЭС, энергоблоки №№ 1-6; Кольской АЭС, энергоблоки №№ 1, 2; Балаковской АЭС, энергоблоки №№ 1-4; Ростовской АЭС, энергоблок № 1;

- система внутриреакторного контроля [2]- на Запорожской АЭС, энергоблоки №№ 1-6; Хмельницкой АЭС, энергоблоки №№ 1, 2; Ровенской АЭС, энергоблоки №№ 1-4; Южно-Украинской АЭС, энергоблоки №№ 1, 2;

- система контроля нейтронного потока [3]- на Запорожской АЭС, энергоблоки №№ 1-6; Хмельницкой АЭС, энергоблоки №№ 1, 2; Южно-Украинской АЭС, энергоблоки №№ 1-3; Ровенской АЭС, энергоблоки №№ 1-4; Армянской АЭС, энергоблок № 2;

- система группового и индивидуального управления [3] - на Ровенской АЭС, энергоблоки №№ 1-3; Запорожской АЭС, энергоблоки №№ 1, 2, 6;

- цифровая управляющая система безопасности на Запорожской АЭС, энергоблоки №№ 1, 2;

- цифровые системы нормальной эксплуатации реакторного и турбинного отделений - на Запорожской АЭС, энергоблоки №№ $1,2,5$;

- комплексная система диагностики - на Ровенской АЭС, энергоблоки №№ 1, 2, 4; Хмельницкой АЭС, энергоблок № 2;

- система регистрации важных параметров эксплуатации «черный ящик» - на Ровенской АЭС, энергоблоки №№ 1-4; Хмельницкой АЭС, энергоблоки №№ 1, 2; Запорожской АЭС, энергоблок № 2;

- центр технической поддержки операторов в аварийных ситуациях - на Ровенской АЭС, энергоблоки №№ 3, 4; Хмельницкой АЭС, энергоблоки №№ 1, 2;

- система автоматического регулирования управляющих систем безопасности - на Хмельницкой АЭС, энергоблок № 2;

- система управления аварией «Течь теплоносителя из первого контура во второй» - на Хмельницкой АЭС, энергоблок № 2; Ровенской АЭС, энергоблок № 4;

- система контроля концентрации борной кислоты (на базе боромеров НАР-И) - на Ровенской АЭС, энергоблоки №№ 1, 2; Армянской АЭС, энергоблок № 2.

ИУС разработаны на базе микропроцессорной системы контроля и управления МСКУ 3М - аппаратно-программной платформы нового, третьего поколения, которая явилась результатом длительной эволюции программно-технических средств для создания ИУС АЭС на основе стандартов, руководящих документов, норм и правил 
Украины, МАГАТЭ и МЭК. Первые поставки оборудования производства СНПО «Импульс» на АЭС начались в 1975 г. (Белоярская, Нововоронежская, Ровенская АЭС). С 1980-х годов на энергоблоках атомных станций СССР и Восточной Европы внедрялись дублированные управляющие вычислительные комплексы СМ-2М. В 1992 г. была создана первая в Украине (и бывшем СССР) цифровая платформа для разработки ИУС АЭС - МСКУ М [4, 5], в 2001 г. - следующее поколение платформы - МСКУ 2М [6], затем МСКУ 3М. В настоящее время заканчивается разработка четвёртого поколения - МСКУ 4М.

\section{Аппаратно-программная платформа ИУс}

МСКУ 3М включает функционально полный набор технических и программных средств, позволяющих компоновать ИУС в соответствии с требованиями конкретного проекта и с соблюдением принципов единичного отказа, независимости, безопасного отказа, диверсности, детерминированности режимов функционирования.

Технические средства МСКУ 3М (программируемые промышленные контроллеры различных классов безопасности и степеней резервирования; промышленные рабочие станции разного функционального назначения; шкафы коммутации; устройства связи с панелями операторов; преобразователи сигналов; устройства электропитания и др.) разработаны на основе элементной базы и комплектующих ведущих мировых фирм-производителей.

Базовыми компонентами ИУС являются программируемые промышленные контроллеры семейства МСКУ [7].

Основные функции МСКУ:

сбор, преобразование, первичная обработка и хранение информации, полученной от объекта;

выполнение в реальном времени функций контроля и управления (регулирование по различным законам, реализация защит, блокировок, пуска и останова оборудования);

обмен информацией с внешними абонентами по интерфейсам с оптоволоконными связями: Ethernet 100BASE-FX, $\mathrm{RS}-485, \mathrm{RS}-422$.

Состав MCKУ определяется особенностями его применения в ИУС и включает:

центральные микропроцессорные контроллеры (КМп); модули связи с объектом (МСO), предназначенные для ввода/вывода дискретных и аналоговых сигналов; модули связи для внешних обменов;

модули контроля собственного оборудования;

панели кроссовые и соединительные для подключения кабелей от объектов.

КМп и модули устанавливаются в монтажные каркасы. Центральная часть МСКУ может быть нерезервированной (один КМп) или резервированной (три КМп).

Основные характеристики МСКУ:

модульная конструкция (возможность компоновки подсистем нижнего уровня ИУС как с одним, так и несколькими шкафами с единой центральной частью);

возможность резервирования как центральной части, так и каналов ввода/вывода;

соответствие жестким требованиям промышленных стандартов;

произвольный порядок размещения МСО в каркасах; возможность установки и замены модулей без отключения питания («горячая» замена);

отсутствие принудительной вентиляции; самодиагностика с локализацией неисправностей до сменного блока;

осуществление электропитания от двух независимых фидеров как переменного, так и постоянного тока;

классы безопасности - 2 и 3 [8], категории без опасности - А и В [9].

средний срок службы - не менее 30 лет.

Программные средства МСКУ ЗМ включают в свой состав системное программное обеспечение (ПО) реального времени; коммуникационное ПО; ПО операторских станций; инструментальное ПО для подготовки, отладки и сопровождения прикладного ПО; тестово-диагностическое ПО.

Программное обеспечение МСКУ 3М соответствует рекомендациям, содержащимся в документах МАГАТЭ: NS-G-1.1 [10], NS-G-1.3 [11] и стандарту IEC 60880 [12]. В частности, применяется программный код, обеспечивающий выполнение функций защит, блокировок, регулирования и сигнализации с детерминированными алгоритмами и временем (в циклическом режиме без использования прерываний и операционных систем) благодаря использованию разработанной в СНПО «Импульс» проблемно-ориентированной системы программирования. Она применяется для программирования алгоритмов регулирования, защит, блокировок, сигнализации. В основе языка программирования лежит набор алгоритмических блоков. Такой подход позволяет автоматизировать генерацию кода прикладных программ, максимально приближенных к виду технологических алгоритмов, представленных заказчиком (проектантом) для проектов ИУС, снизить вероятность ошибок проектирования, упростить процесс верификации и сделать его более достоверным.

Перед внедрением в эксплуатацию ПО ИУС подвергается полной валидации и верификации, обеспечивается его кибербезопасность.

Снижение вероятности возникновения необнаруженных в ПО ошибок, обусловленных ошибками проектирования или кодирования, достигается:

независимой верификацией программного обеспечения на всех стадиях жизненного цикла;

тестированием отдельных элементов программного обеспечения;

комплексным тестированием функций ИУС (при комплексной отладке и в процессе предварительных испытаний) с использованием математической модели ядерной установки;

апробацией технических решений во время опытной эксплуатации пилотных образцов ИУС;

авторским сопровождением.

\section{Основные особенности ИУс}

Основными особенностями ИУС являются:

- возможность построения ИУС с различными схемами мажорирования («2 из 3», «2 из 4» и др.);

- устойчивость к единичным и кратным неисправностям за счет резервированных структур, в том числе резервирования аналого-цифровых преобразователей и устройств управления исполнительными механизмами;

- применение принципов диверсности;

- минимум кабельных связей за счет: а) применения выносных цифровых контроллеров для дистанционного управления, индикации и сигнализации на БЩУ (РЩУ); б) цифровой оптической передачи данных; 
- возможность технического обслуживания ИУС раздельно по каждому каналу с сохранением работоспособности по всем функциям;

- непрерывный контроль оборудования ИУС.

ИУС спроектированы таким образом, что в процессе функционирования выполняется автоматический контроль работоспособности и правильности выполнения их функций. Автоматический контроль обеспечивает обнаружение неисправностей технических средств ИУС.

В соответствии с рекомендациями NS-G-1.3 и стандартом IEC 60987 [13], кроме традиционных методов оперативного контроля и диагностирования неисправностей (например, контроль сохранности в памяти программ и констант, контроль превышения лимита времени выполнения операций, контроль правильности передачи информации по линиям связи), реализованы следующие методы:

- встроенное диагностирование внутри блоков элементов:

- защита и диагностирование выходных каналов блоков управления механизмами в части ложного срабатывания выходных ключей;

- встроенное тестовое диагностирование входных каналов блоков управления механизмами и ввода сигналов от ключей БЩУ, РЩУ в фоновом режиме;

- диагностирование методом сравнения данных резервированных блоков:

- сравнение состояния идентичных входных-выходных каналов в резервированных блоках для обнаружения и локализации неисправностей;

- сравнение переменных состояния резервированных блоков для обнаружения, локализации расхождения выходных значений и выполнения автоматических процедур выравнивания этих значений.

П р и м е р ы:

выравнивание значений входного сигнала от датчика по трем измерениям («медианное выравнивание» по алгоритму медианного фильтра);

выравнивание значений элементов памяти.

Вторая процедура необходима не только для компенсации неисправностей, но и для корректной работы программного обеспечения в блоке элементов, установленном из ЗИП:

выравнивания значений элементов оперативной памяти;

выравнивания значений настроечных параметров в энергонезависимой памяти (значений уставок, задержек для алгоритмов защит, блокировок или значений параметров для алгоритмов регуляторов).

\section{Выводы}

Совокупность ИУС, производимых и разрабатываемых НПО «Импульс», обеспечивает построение современных полнофункциональных АСУ ТП перспективных энергоблоков с реактором типа ВВЭР, реализуя выполнение всех важных для безопасности АЭС функций, в частности:

измерение нейтронной мощности реакторной установки; формирование и выдачу сигналов предупредительной и аварийной защит;

формирование и выдачу команд защиты для предотвращения повреждения оборудования энергоблока;

оповещение персонала о нарушениях условий безопасной эксплуатации энергоблока; контроль технического состояния и режимов работы технологического оборудования;

диагностирование технических средств и программного обеспечения ИУС.

При создании ИУС учтены современные тенденции в реализации АСУ ТП перспективных энергоблоков, а также требования по надежности, вызванные переоценкой безопасности АЭС в связи с аварией на АЭС «Фукусима-1».

Очевидны преимущества реализации АСУ ТП одним поставщиком (в кооперации с другими фирмами):

максимальная унификация оборудования и интерфейсов; единые информационная среда и система кодирования; снижение затрат на инжиниринг;

сдача АСУ ТП заказчику как законченной системы;

удешевление эксплуатационных расходов;

упрощение сервисного обслуживания;

конкурентоспособная стоимость.

Большой опыт промышленной эксплуатации подтвердил хорошие эксплуатационные характеристики ИУС.

Высокую оценку получили ИУС в отчете независимой экспертной миссии «Анализ МАГАТЭ цифровых ИУС, разработанных СНПО “Импульс"», проведенной в апреле 2013 г. Как было отмечено, качество работ по разработке, изготовлению, испытаниям и сопровождению эксплуатации ИУС высокое; проанализированные ИУС согласуются с соответствующими разделами Руководства МАГАТЭ по безопасности NS-G-1.3; дана высокая оценка системам автоматического контроля и диагностирования оборудования ИУС. Процессы диагностирования в реальном масштабе времени обеспечивают эффективное и своевременное выявление неисправных компонентов.

\section{Список использованной литературы}

1. Горелик $A$. X. Опыт разработки новых и поэтапной реконструкции действующих информационно-вычислительных систем энергоблоков с реактором ВВЭР-1000 / А. Х. Горелик, В. В. Елисеев, В. А. Орловский // Ядерная и радиационная безопасность. 2005. - № 1. - C. 91-96.

2. Горелик $A$. X. Концепция модернизации систем внутриреакторного контроля ВВЭР-1000 АЭС Украины / А. Х. Горелик, В. В. Елисеев, А. С. Кужиль, В. А. Орловский, С. П. Падун, В. Ф. Якубов // Ядерная и радиационная безопасность. -2005 . № 4. - С. 53-65.

3. Системы управления и защиты ядерных реакторов / М. А. Ястребенецкий [и др.]; под ред. М. А. Ястребенецкого. - К. Основа-Принт, 2011. - 768 с. - (Безопасность атомных станций).

4. Елисеев $B . \quad B$. Микропроцессорная система контроля и управления МСКУ М / В. В. Елисеев, Г. Ю. Пивоваров и др. // Приборы и системы управления. - 1994 - № 9. - С. 28-31.

5. Горелик $A$. X. АСУ энергоблоками тепловых и атомных электростанций на базе средств МСКУ М // А. Х. Горелик, Я. Г. Хаит и др. // Приборы и системы управления. - 1996. - № 10.

6. Елисеев B. B. Микропроцессорная система контроля и управления МСКУ 2М // В. В. Елисеев, Г. Ю. Пивоваров и др. // Промышленные АСУ и контроллеры. - 2002. - № 3. - С. 1-5.

7. Чвиров Ю. А. Микропроцессорные субкомплексы контроля и управления МСКУ 2, МСКУ 3 для АСУ ТП АЭС / Ю. А. Чвиров, Г. Н. Скляров // В сб. «Системы контроля и управления технологическими процессами» под общей ред. В. В. Елисеева. Луганск: Светлица, 2006. - 440 с.

8. НП 306.2141-2008. Основные положения безопасности атомных станций. - К.: Гос. комитет ядерного регулирования Украины, 2008

9. IEC 61226. Nuclear power plants - Instrumentation and control important to safety - Classification. - 2005. 
10. IAEA NS-G-1.1. Software for computer based systems important to safety in nuclear power plants. Safety guide. - Vienna, 2000.

11. IAEA NS- G-1.3. Instrumentation and Control Systems Important to Safety in Nuclear Power Plants. Safety guide. - Vienna, 2002.

12. IEC 60880. Nuclear power plants - Instrumentation and control systems important to safety - Software aspects for computerbased systems performing category A functions. - 2006 .

13. IEC 60987. Nuclear power plants - Instrumentation and control important to safety - Hardware design requirements for computer-based systems. - 2007.

\section{References}

1. Gorelik A. Kh. Experience in designing new computer information systems for units with a VVER-1000 reactor and stage-by-stage reconstruction of operating ones / A. Kh. Gorelik, V. V. Yelisyeyev, V. A. Orlovskii // Iadernaia i radiatsionnaia bezopasnost'. - 2005. No. 1. - P. 91-96. (Rus)

2. Gorelik A. Kh. Modernization concept for in-core monitoring systems of VVER-1000 of Ukrainian NPPs / A. Kh. Gorelik, V. V. Yelisyeyev, A. S. Kuzhil', V. A. Orlovskii, S. P. Padun, V. F. Iakubov // Iadernaia i radiatsionnaia bezopasnost'. - 2005. No. 4. - P. 53-65. (Rus)

3. Nuclear reactor control and protection systems / M. A. Iastrebenetskii [et al.]; edited by M. A. Iastrebenetskii. - K.: Osnova-Print, 2011. - 768 p. - (Safety of nuclear power plants). (Rus)

4. Yelisyeyev $V . V$. MSKU M microprocessor instrumentation and control system / V. V. Yelisyeyev, G. Iu. Pivovarov, et al. // Pribory i sistemy upravleniia. - 1994 - No. 9. - P. 28-31. (Rus)

5. Gorelik A. Kh. I\&Cs of units of thermal and nuclear power plants based on MSKU M facilities // A. Kh. Gorelik, Ia. G. Khait, et al. // Pribory i sistemy upravleniia. - 1996. - No. 10. (Rus)

6. Yelisyeyev $V . V$. MSKU $2 \mathrm{M}$ microprocessor instrumentation and control system // V. V. Yelisyeyev, G. Iu. Pivovarov, et al. // Promyshlennye ASU i kontrollery. - 2002. - No. 3. - P. 1-5. (Rus)
7. Chvirov Iu. A. MSKU 2, MSKU 3 microprocessor instrumentation and control subcomplexes (programmable logic controllers) for I\&Cs of NPPs / Iu. A. Chvirov, G. N. Skliarov // In collected volume "Sistemy kontrolia i upravleniia tekhnologicheskimi protsessami" under the general editorship of V. V. Yelisyeyev. - Lugansk: Svetlitsa, 2006. 440 p. (Rus)

8. NP 306.2141-2008. Basic provisions of safety of nuclear power plants. - K.: Gos. komitet iadernogo regulirovaniia Ukrainy (State Nuclear Regulatory Inspectorate of Ukraine), 2008. (Rus)

9. IEC 61226. Nuclear power plants - Instrumentation and control important to safety - Classification. - 2005. (En)

10. IAEA NS-G-1.1. Software for computer based systems important to safety in nuclear power plants. Safety guide. - Vienna, 2000. (En)

11. IAEA NS-G-1.3. Instrumentation and Control Systems Important to Safety in Nuclear Power Plants. Safety guide. - Vienna, 2002. (En)

12. IEC 60880. Nuclear power plants - Instrumentation and control systems important to safety - Software aspects for computerbased systems performing category A functions. - 2006. (En)

13. IEC 60987. Nuclear power plants - Instrumentation and control important to safety - Hardware design requirements for computer-based systems. - 2007. (En) 